\title{
Aa. Vv., «Cahiers Claude Simon», n. 3, sous la direction de Jean-Yves Laurichesse
}

\section{Massimiliano Catoni}

\section{Q OpenEdition}

1 Journals

\section{Edizione digitale}

URL: http://journals.openedition.org/studifrancesi/8077

DOI: 10.4000/studifrancesi.8077

ISSN: 2421-5856

\section{Editore}

Rosenberg \& Sellier

\section{Edizione cartacea}

Data di pubblicazione: 1 juillet 2009

Paginazione: 441

ISSN: 0039-2944

\section{Notizia bibliografica digitale}

Massimiliano Catoni, «Aa. VV., «Cahiers Claude Simon», n. 3, sous la direction de Jean-Yves

Laurichesse», Studi Francesi [Online], 158 (LIII | II) | 2009, online dal 30 novembre 2015, consultato il 13 janvier 2021. URL: http://journals.openedition.org/studifrancesi/8077 ; DOI: https://doi.org/10.4000/ studifrancesi.8077

Questo documento è stato generato automaticamente il 13 janvier 2021.

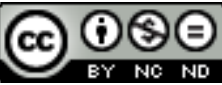

Studi Francesi è distribuita con Licenza Creative Commons Attribuzione - Non commerciale - Non opere derivate 4.0 Internazionale. 


\title{
Aa. Vv., «Cahiers Claude Simon», n. 3 , sous la direction de Jean-Yves Laurichesse
}

\author{
Massimiliano Catoni
}

\section{NOTIZIA}

«Cahiers Claude Simon», n. 3, sous la direction de Jean-Yves LAURICHESSE, 2007, pp. 154.

1 Non c'è dubbio che l'ultimo numero dei «Cahiers Claude Simon» abbia l'ambizione di proporre un confronto tra due giganti della letteratura francese: Simon e Sartre. L'impressione è che gli interventi raccolti nell'ampia sezione centrale di questo volume mirino soprattutto a dare un volto riconoscibile a quel misto di risentimento e di antagonismo che impedì a questi due scrittori di abbandonarsi a una ricezione autentica (priva cioè di sarcasmi e di stroncature sommarie) delle rispettive opere. In effetti, l'unica cosa che sembrano avere in comune Simon e Sartre è una sorda ostilità reciproca, mai seriamente deflagrata in scontro aperto. Per il resto dobbiamo registrare una diversità che non è tanto stilistica, bensì antropologica. Che distanza tra la fede incrollabile di Sartre nell'azione dell'uomo e lo scetticismo pungente di cui Simon ci dà testimonianza nei suoi scritti. Fedele al suo glaciale riserbo, simon si è progressivamente defilato, confinandosi nello spazio magico dei suoi romanzi, mentre Sartre si calava nell'agone della Storia con dedizione eroica.

2 Tra i contributi, si segnala quello di Didier ALEXANDRE (Quelques réflexions sur les relations de Claude Simon à Jean-Paul Sartre, pp. 87-104), che ha provato a chiarire la diversità di questi due approcci ricordandoci come «l'homme de Sartre demeure soumis à l'histoire présente, économique, sociale, politique, culturelle, tandis que celui de simon ne saurait être l'homme de l'histoire présente» (pp. 103-104). Dunque è come se Simon, nell'affrontare le tragedie del suo tempo, mirasse a coglierne l'elemento universale, mentre Sartre sembra soggiogato unicamente dal dato contingente. Ma perché Simon, 
che pure nei suoi romanzi non ha mai smesso d'occuparsi della Storia, finì per asserragliarsi in un oltranzismo formalista e risentito verso qualunque tipo di letteratura che vedesse nel linguaggio uno strumento al servizio delle idee? E perché Sartre, che pure non era stato avaro di elogi nei confronti di nouveaux romanciers come Butor e Sarraute, così distanti dalla sua visione del mondo e della letteratura, finse d'ignorare Simon, assai più prossimo al suo universo letterario, fino in fondo?

Ricostruendo con capillare attenzione il paesaggio emotivo dei primi romanzi di Simon, Jean-François LOUETTE (Claude Simon et Sartre: les premiers romans, pp. 63-85) nota come molte delle idee che affolleranno i sartriani Chemins de la liberté balenino già in queste pagine giovanili. Senza sapere ancora nulla l'uno dell'altro, Simon e Sartre si trovarono dunque a marciare lungo lo stesso cammino. Fu il grande successo avuto da Sartre a spingere Simon verso un'altra direzione. Ecco perché Louette sospetta che il formalismo tanto decantato da Simon nel dopoguerra non sia che una strategia per «échapper à Sartre» (p. 67). A suo giudizio, «ce qui expliquerait la grande fureur que Simon n'a jamais cessé d'exprimer à l'endroit de Sartre, ce serait qu'il a vécu en 1945, $\mathrm{du}$ fait de Sartre, un vol de thèmes, et de succès» (p. 76). Insomma Simon divenne Simon per sottrarsi all'ombra spaventosa proiettata dal principe dell'esistenzialismo, per riservarsi una nuova zona di autonomia e originalità. Ecco spiegato il risentimento di Simon nei confronti di Sartre. Un risentimento che è testimoniato anche dallo scritto inedito incluso in questo volume dei "Cahiers» e intitolato: Claude Simon: 1947-1957. Dixième anniversaire de "l'engagement" ou Monsieur de Norpois et la "littérature banane" (pp. 131-135) nel quale Simon non fa che ribaltare una ad una le tesi postulate da Sartre in Qu'est-ce que la littérature, contestandogli, con un'ironia che sconfina spesso nel sarcasmo, l'idea che la letteratura possa avere una qualsiasi utilità sociale o storica. Affidiamo la conclusione a questa suggestiva ipotesi di Louette: «malgré la constance de cette polémique, Simon devenu "grand" me semble un Sartre qui serait resté fidèle, du moins dans la métaphysique que suppose sa technique romanesque, à la contingence et à l'absurde» (p. 79). 